\title{
A model for Construction Project Management extranets
}

\author{
Nuria Forcada, Miquel Casals, Xavier Roca \\ Polytechnic University of Catalonia, Department of Construction Engineering \\ C/Colom 11, Edifici TR-5, 08221 Terrassa, Barcelona, Spain \\ nuria.forcada@upc.es
}

\begin{abstract}
In AEC each participant of a construction project (designer, the constructor, etc) takes part in many other projects and each of these groups of participants are probably working in collaborative spaces. What happens then, when for instance the designer must hold as many collaborative spaces as projects he carries on? In the construction sector, each project is unique and the group of people, who are working on it, is different. Among the drawbacks of several of these applications is the lack of support provided to users. In this Paper a draft of guidelines for the users of extranets for the management of construction projects will be exposed. The aim of this project is to establish the necessary basis and criteria to facilitate an integral project management and to help SMEs using Information and Communication Technologies so as to reduce the fear to this new tool from such a traditional and fragmented sector.

To do so, we have developed a new working and organizational standard model for the information and communication system for the company. The scope of this project is that all the companies (specially SMEs of the construction sector) were capable to identify their necessities, define their process improvement strategies (using ICT) and learn in a reliable way the benefits of using this new technology. In contrary, in an early future this technologies will become an absolutely critic barrier for this companies to participate in many projects.

This model will serve as a demonstration for all the participants of a construction project (architect, constructor, client, suppliers, etc.) that all the information functions (consult and storage), communication, data transmission, etc. related to an specific project can be done by using new technologies (like extranets or collaboration tools) and with more advantages than the traditional working methods.
\end{abstract}

KEYWORDS: guidelines, extranets, document management.

\section{INTRODUCCIÓN}

AEC (Architecture, Engineering and Construction) firms tend to be involved in a portion of the building process. They team up in different combinations for different projects. AEC firms typically have far less optimised work processes, and they have invested far less in computer technology. However, the final product (a building or a plant) requires ongoing management that is affected by the quality of the information provided to run it. Internet collaboration tools can affect a significant paradigm shift in AEC by unifying the disparate project teams of architecture, construction and owner/operator for the first time ever.

Extranets, or collaboration tools, can act as a breeding ground for true integration between discrete processes of all major participants in the industry, by themselves, they may save only a small portion of efficiency throughout the entire lifecycle of a building, but they are a critical first step for our industry to begin truly integrating data such as legacy, and in-house applications and systems. (Weisberg, S, 2002)

Successful online collaboration requires that all project team members - including clientsunderstand how to use the technology, are comfortable with it, and actually use it to manage projects.

\section{THE EVOLUTION OF DOCUMENT MANAGEMENT}

The effective management of all the information needed for a construction project from the conception stage to the construction and maintenance of the building is a basic requirement for the success of the project. All participants of construction projects know the impact on overall construction costs of delays, missing or contradictory information, mistakes, etc.

Documents in the construction sector have not undergone major changes since the middle of the $20^{\text {th }}$ century. Plan drawings, bills, specifications, etc. look as they did some decades ago. The technology for producing, managing, duplicating 
and distributing such documents has, however, undergone a number of fundamental changes. (Björk, 2001)

Firstly, the introduction of photocopying in the 60 's that reduced the cost of duplicating information.

Afterwards, the introduction of personal computing for the day-to-day work during the 80's and the mass utilization of CAD-systems, wordprocessing and other software helped to reuse information.

In the 80 's the fax became also a popular data transfer method and was used to handle offers, send graphics, etc. but was not useful for larger drawings or documents.

Finally, in the late 80 's and early 90's Internet made possible the document transfer via mail that was a great step for the document management. Currently, it's nearly 10 years from the beginning of the mass commercialisation of Internet, the media that has progressed in an exponential way.

In its original form, the Internet was used to show information, and send information via mail. It was an important advance in document management and communication among partners but other important requirements in the construction management projects were still not addressed. This speeded up the document transfer, but in terms of document management, this hardly offered any improvement over the current situation since finding a document in another person's PC may be even more difficult than finding it on his shelves. Finding a document may often as a last resort require asking a person to deliver it.

The evolution tended to join communities of users, professionals, etc. in different spaces that were called Virtual Communities and Portals. A portal is 'The web page where to aggregate contents and functionalities, organized in a way that facilitates the navigation and gives the users an entrance to the Net with a huge range of options'. Therefore, users have the services and products of an area of knowledge that might need all together.

Later, companies felt the necessity to offer services and improve their contents. Now, the strategy of Internet is not only to 'be' there but also to 'do'.

Not only after some years of the beginning of the first portals, the construction sector entered in Internet.

The most sophisticated method currently in use is to use extranets or document management systems where the documents are stored centrally on a web server and users interact with this central repository though interfaces implemented using standard web browsers. (Björk, 2002)

Many different names have been used by both service providers and researchers to denote such systems, including Document Management System, Project Extranet, Project web, Project Bank, Project Specific Web Site, Document Pool, Project Information Management System, and Virtual Project. Some authors give these terms slightly different meanings. A project specific web site (T. Thorpe, S. Mead 2001) can, for instance include quite a lot of general information about a building project (i.e. live web cams) in addition to the basic Electronic Document Management functionality.

\section{ORGANISATION STANDARD MODEL}

The growing number of international projects and widespread adoption of project management leads to a significant increase in the number of individuals across the world that need to communicate within and understand the field of Project Management.

In the construction sector, most of the projects are developed by many different partners who are often geographically dispersed and have to coordinate their activities. They need to exchange information electronically; to be connected to a controlled-access web-based workspace, in order to share data and information; to create structured electronic databases; to provide information and products and services electronically; to interact with customer and provide fast and effective on line assistance, etc.

There seems to be some disagreement about the levels of participation and interest by the three main groups comprising AEC: designers (architects and engineers), contractors, and owner operators/clients.

But the main problem is how each participant deals with his data and how can the management of his enterprise can be compatible with the management of a project. (Burchard, B, 2001)

There is a clear need of a framework that enables all parties to communicate and exchange information via IT.

If construction organizations are to benefit from IT investments, then new guidelines for Small and Medium Enterprises are required such that construction business participants can understand and feel fully confident in applying them.

Therefore, it's necessary to have a common basis for all organizations due to the possibility of each 
organization to be involved in many other projects.

These guidelines should be focused on the contents of the system so as to improve the actual management of each organization and to increase the efficiency of the team as a whole.

On top of that, some organizations have already implemented some Management Systems according to ISO 9000, ISO 14000 , OSHA 18000 , etc. so it's obvious that these guidelines should not be against these norms. They should complement them.

If this kind of framework exists, the online services industry will continue to solidify and services providers will be compelled to adjust their offerings. (Forcada N. et al, 2002)

Guides and/or standards can also be seen as a way of making the tacit explicit by formally documenting the accepted 'best practices' of practitioners in order to make them more readily transferable to novices.

\subsection{Background}

Some of the characteristics of the construction sector are:

- $\quad$ specifications for design and manufacturing in all disciplines is of major importance,

- there is a need for understanding globally, utilizing a common communication language;

- the use of computer aided systems prevails, e.g. CAD, CAM, PDM;

- the tendency for use of sub-contracting, outsourcing and consultancy is increasing;

- the quality management systems according to the ISO 9000-series (including supporting standards) is of high priority to all industries;

- the technical product documentation may be regarded as a basis for contractual interpretation.

All these restrictions make necessary a standardization and coordination of information throughout the product life cycle to facilitate preparation, management, storage, reproduction, exchange and use of these information.

\subsection{Expected benefits}

Implementation of a guide for project document management:

- reduces costs;

- assures quality;
- implies shorter elapsed time from design concept to market product;

- provides a platform for communication;

- reduces the risk of misinterpretation.

The increasing utilization of Information Technology (IT) within technical product documentation has highlighted several new topics, of which the following have been identified as being of particular importance:

- classification;

- meta data;

- document management data;

- document technical contents;

- product modelling.

We are focusing on the first three characteristics to solve part of these problems.

\subsection{The Process to create an organizational Standard Model for document management}

\subsubsection{Mapping participants and processes}

This guide is intended for use by all those involved in the construction project: client, design consultants, contractors, sub-contractors, suppliers, control laboratories, etc. but the current extranets that are in the market are focused on the monitoring of the project.

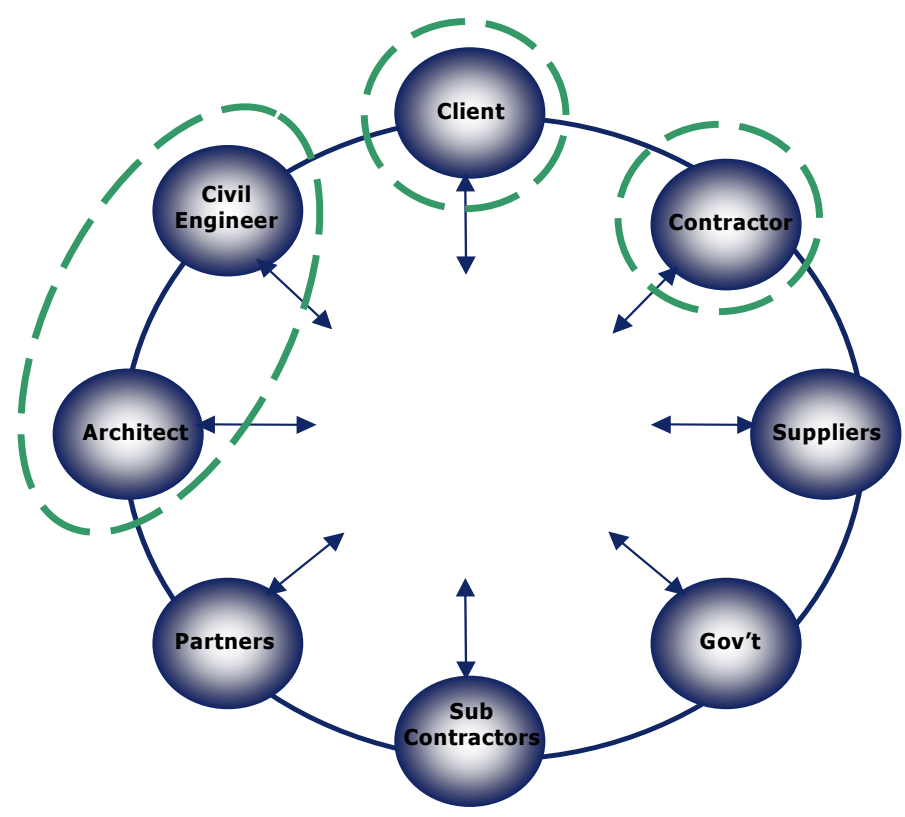

Figure 1. Participants of a construction project

Firstly, we have mapped all the stages of a construction project. We have used RIBA Plan of work (RIBA 1997), which is a standard method of 
operation for the construction of buildings and is widely accepted as an operational model throughout the building industry. It represents a logical sequence of events that should ensure that sound and timely decisions are made.

The phases and stages that have been chosen to map all the activities and documents to be transferred are:

\section{- Pre-design phase}

Throughout the Pre-design Phase the client's need is progressively defined and assessed with the aim of determining the need for a construction project solution.

- Design phase

In this phase the defined client's need is developed into an appropriate design solution. At the end of this phase, the aim is to secure full financial authority to proceed.

- Preparing to build phase

This phase is based on producing the final information of the project and the tendering.

- Construction phase

It is here where the full benefits of the coordination and communication earlier in the process may be fully realized. Potentially, any changes in the client's requirements will be minimal.

- Post-construction phase

Upon completion of the Construction Phase the process continues into the Post-Construction phase, which aim to continually monitor and manage the maintenance needs of the constructed facility.

Once we had mapped all the participants of the process of a construction project and all the phases and stages, from these information we generated a matrix to create a friendly and easy to understand organization of the contents. The next figure shows the basic organizational matrix.

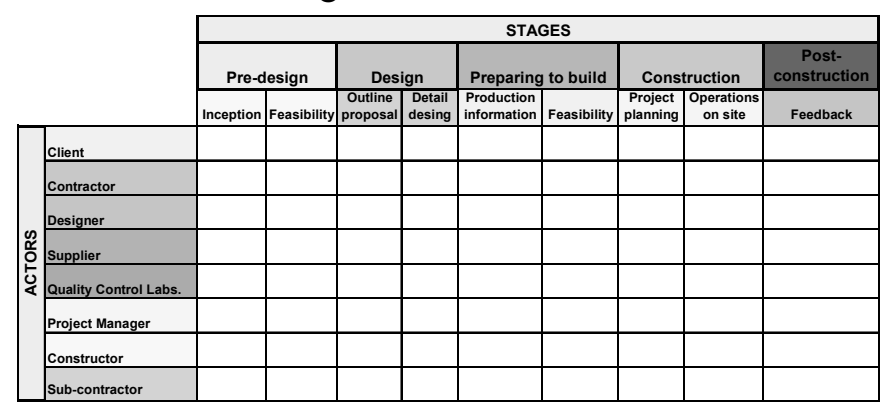

Figure 2. Basic matrix to access the guide information
From each PHASE and STAGE we have defined all the documents, which will be produced in those part of the project.

The main characteristic was to define the most important information of each document so as to have the whole relationship among all the related information.

From each document we have defined a set of metadata.

\subsubsection{Document metadata}

In common language the word document usually means a container of information (usually on paper) containing written or drawn information for a particular purpose in a structured way.

Traditionally, a document is a piece of paper or a collection of papers, for instance, a memo, a letter, a mission statement, a bill of materials or a customer invoice. The paper presented information, usually text or text and graphics, is laid out on physical pages.

Over the last decade, the term "document" has undergone a radical change in definition. In part, this change is due to IT. Information technology is now capable of producing a new electronic document, which can house graphics, text, CAD, and multimedia objects, (i.e. audio or video clips). Documents are processed and stored in electronic form, not as physical objects, but as digital ones. The document is no longer the place where words are put on a page, but rather a collection of elements or objects related to a particular topic, brought together. Therefore, a new definition of a document in electronic age emerges.

An Electronic Document is an information container in electronic form, which gathers together information from a variety of sources, in a number of formats, around a specific topic to meet the needs of a particular individual.

A user can create an electronic document on a personal computer without creating a paper document. An electronic document can be identified, taken and stored from Internet, Intranet and Extranet in an electronic manner. A single electronic document can be processed and transmitted to others on networks at the same work place or even by users around the world via Internet. The document in an electronic document management system is really an electronic object since it is neither a piece of paper nor a film.

One advantage of the electronic document is that it is not necessary to have the same media for every user. An electronic document can be delivered in any format that meets the needs of user. 
Central to the idea of a document is usually that it can be easily transferred, stored and handled as a unit (Löwnertz 1998).

After a brief description of the document concept we are able to categorize and define metadata for each of the electronic documents generated in the whole life cycle of a project.

Electronic documents can be categorized according to different purposes:

\begin{tabular}{|ll|}
\hline \multicolumn{2}{|c|}{ DOCUMENT } \\
\hline Document name: & \\
\hline Description: & \\
\hline Late submital date & (phase): \\
\hline Author: & Publication date: \\
\hline Reviewer: & $\begin{array}{l}\text { Revision date: } \\
\text { Revision number: }\end{array}$ \\
\hline Modifier: & $\begin{array}{l}\text { Modification date: } \\
\text { Modification number: } \\
\\
\text { Type of modification: }\end{array}$ \\
\hline Reader: & $\begin{array}{l}\text { Access date: } \\
\text { Phase reader: }\end{array}$ \\
\hline Users: & Phase user: \\
\hline Type of document: & \\
\hline Atributes: & \\
\hline Related documents: & \\
\hline
\end{tabular}

Figure 3. Metadata assigned to each document

For each document we have defined the next set of metadata:

\section{Document name}

Each document name is formed by 2letters +3 numbers +4 letters +4 numbers.

The first two letters concert to the name of the project.

The first three numbers concern to a consecutive relation of documents with the same characteristics.

The following two letters concern to the initials of the attribute of the document and are written in capital letters.

The last two letters concert to the initials of the type of document and should be in small letters.

The last four numbers are the latest publication, revision or modification date. The first two numbers are the year and the others are the month. For example, if we have a Site Note of the Forum project that was modified on the $3^{\text {rd }}$ of November 2002, its document name will be:

FO001SNdc0211

\section{Description}

It depends on the author necessities. It can be notes for a better understanding of the document or a global description of the document.
Late submittal date (phase)

The late submittal date is the phase (design, construction, etc) and stages (inception, feasibility, etc.) when the document must be submitted for the right functioning of the project.

\section{Actors:}

The author is the person who has created the document and can view, upload, create and delete the document.

Reviewer: the person who has the right to review the document and can view and upload it

Modifier: the person who can modify a document as well as view and upload it.

Reader: the person who has access to the document so he can view it.

Users: the person/s who will need this document for the completion of the project. For example the document 003PAdw0301 an architecture drawing of the project, should be submitted about the middle of the design phase and by the middle of the detail design activity. The author of this document will be the architect and the civil engineer will use it during the design phase.

These attributes might change along the different phases of the project. At the beginning all the drawings will be used by the designers but once in the construction phase the contractors, suppliers, etc. will use them so we should define an attribute relating the information of each partner to the stage or phase when they need the information called 'Phase reader'.

\section{Type of document}

The format of the document is included in this information. If it's a word document, an excel document, an AutoCAD document, etc.

The different types of documents are: word, excel, access, power point, winproject, CAD, image, web, e-mail, etc.

dc: word DoCument .DoC

$\mathrm{xl}$ : eXceL document.XLs

md: access document .MDb

pp: Power Point document .PPt

wp: Win Project document

dw: DraWing document .DWg

im:. IMage drawing .gif, .tiff, .jpg, bmp

hm: web document .HtMl, .HtM

\section{Attributes}

We can classify each document depending on the stored information. The attributes can be:

SN: Site Notes

ME: Meetings

CO: Change Order 
RE: REports

RI: Request for Information

CT: ConTract

BD: BuDget

CM: Cost Management

P_: Project

PA : Project Architecture

PS: Project Structures

PM: Project Mechanical

PE: Project Electrical

PQ: Project Quality

PS: Project Health and Safety

PE: Project Environment

PP: Project Planning

PS: Project Specifications

LE: Letter

RC: ReCeipt

IN: Invoice

TS: Technical Specification

\section{Related documents}

Set of documents that are needed for the entire understanding of it. For example a related document of a Request for Information might be the drawing that we are asking for.

The related document of: FO005RIdc0302 might be: FO024PAdw0211.

\subsubsection{Guidelines}

After mapping all documents to be transferred and all the communication among all the participants in each phase and activity of the project we proceeded developing a set of guidelines to help SMEs archiving their project information so as to use a common framework when working with construction extranets.

It's a generic and global model for whatever construction project.

These guidelines are defined for the entire project and for all the stages.

The main purpose is to have all the information related to one actor so as he has the following data:

- When to deliver a document

- Who will deliver the document and when will it be delivered

- Compulsory communications to make

\section{CONCLUSIONS}

New technologies have changed the way of working in many sectors and the last decade the construction sector has also started to notice this influence. Many businesses related to construction have started to use extranets and/or cooperation portals but the lack of standardization of the processes makes it more difficult to deal with.

The basis and criteria to facilitate an integral project management and to help SMEs using Information and Communication Technologies that we are exposing will reduce the fear to these new tools from such a traditional and fragmented sector.

Once these standards are accepted, the adoption of information technologies will be deepened, construction business processes will be streamlined, construction markets will be expanded, and construction technology will be improved. To facilitate the benefits provided by systems, owners and constructions must, respectively, restructure their organizations for better competitive positions. The restructuring will be both intra and inter organizational.

\section{REFERENCES}

Bjork 2001, Document management -a key IT technology for the construction industry,ecce conference

Bjork 2002, The impact of Electronic Document management on Construction Information Management, Conference Proceedings distributing knowledge in building, CIB w78 conference 2002, Aarhus School of Architecture, 12-14 june 2002

Burchard, B, 2001. AEC Project Management ONLINE. Cadalyst

Casals, M, Forcada, N \& Roca, X., (2002). State of the art of implementing new technologies for the management of construction projects in Spain. Proceedings of eWork and eBusiness in Architecture, Engineering and Construction, ISBN 905809507 X Portoroz, Slovenia, 153158

Forcada, N, Peñaranda, F, \& Roca, X., (2002). Guidelines for implementing web based models for construction management, the lack. Proceedings of eWork and eBusiness in Architecture, Engineering and Construction, ISBN 905809507 X Portoroz, Slovenia, 165166

Löwnertz, K. 1998. Change and Exchange Electronic Document Management in Building Design, Licentiate Thesis, Dept. of Construction Management and Organisation, Royal Institute of technology, Stockholm, Sweden.

Thorpe,T., Mead S. , 2001 Project-çspecific Web Sites: Friends or FOE? Journal of Construction Engineering and Management, October, Vol 127 (2001), Issue 5 pp. 406-413

Weisberg, S, 2001. I-Collaboration, State of the Industry. Cadalyst 